\title{
Art and culture in the COVID-19 era: for a consumer-oriented approach
}

\author{
Anne-Sophie V. Radermecker ${ }^{1,2} \mathbb{D}$
}

Received: 13 July 2020 / Accepted: 23 September 2020 / Published online: 2 November 2020

(c) Springer Nature Switzerland AG 2020

\begin{abstract}
Since the outbreak of the Coronavirus pandemic, the arts and culture sector has been experiencing a paradoxical situation. While the demand for cultural and creative content has intensified throughout the lockdown period-and digital access has become more critical than ever before--economic indicators predict that the cultural sector will be one of the most affected, and probably one of the slowest to recover. Beyond short-term initiatives such as surveys or data collection aiming to provide artists and intermediaries with financial and logistical supports, both academics and practitioners must engage in joined-up thinking on the future of art consumption, especially from a consumer's perspective. This commentary paper addresses the main challenges faced by the economy of arts and culture in times of global health crisis by pinpointing the specificities of cultural goods and services. More specifically, the paper shows the extent to which traditional patterns of consumption have been affected, and what research is needed to develop sustainable solutions. We argue that consumers will be critical players in the recovery process, and four research directions are suggested accordingly: (1) data collection on consumers' cultural practices; (2) consumers and the digital cultural experience; (3) consumers' engagement and loyalty in the arts and culture; and (4) consumers' well-being.
\end{abstract}

Keywords Cultural management $\cdot$ Cultural economics $\cdot$ Art consumption $\cdot$ Times of crisis · Digital consumption · Consumers' behaviors

Anne-Sophie V. Radermecker

Anne-Sophie.Radermecker@ulb.be

1 Duke Art Law and Markets Initiative, Duke University, Durham, NC, USA

2 Department of History, Arts and Archaeology-Cultural Management, Faculty of Philosophy and Social Sciences, Université Libre de Bruxelles, Avenue Jeanne 56, J56.2.101 (CP103), 1050 Brussels, Belgium 


\section{Introduction}

On 11 March 2020, the World Health Organization (WHO) declared COVID-19 a global pandemic. Amongst the main emergency measures taken by local governments was the temporary suspension of all social, cultural, leisure and recreation activities, followed by the closing of non-essential businesses, including cultural institutions and industries. By contrast, the demand for cultural and creative content has intensified throughout the lockdown period, with digital access having become more critical than ever before. Paradoxically, despite the crucial role played by culture in times of isolation and resiliency, economic indicators predict that the cultural sector will be one of the most affected by, and probably one of the latest to recover from the pandemic and its consequences (UNESCO 2020). The systemic uncertainty created by the crisis has indeed generated asymmetric effects on the arts and culture, and complicated the decision-making process for both suppliers and consumers. Another reason is the multifaceted nature of the supply and demand for the arts and culture, which strongly depends on social and experiential interactions (Hirschman and Holbrook 1982; Botti 2000; Colbert and St-James 2014). Both cultural goods and services are also remarkably heterogeneous, for they are concerned with a broad range of artistic disciplines characterized by different distribution channels and consumption modalities (e.g., purchase, participation, immersion, etc.).

In a context of generalized shutdown, immediate reactions have emanated from the cultural sector. The first priority of stakeholders has been to continue paying artists and employees, and to maintain a minimum level of activity by using digital technologies, as a consequence of the crisis's "inventiveness shock" (Négrier and Teillet, 2020). ${ }^{1}$ In parallel, sectorial representation bodies, governments, and private organizations have carried out large-scale surveys amongst international, national, and local cultural players. The goal of these surveys was to report information from the field to policymakers to justify the logistical and financial support necessary for the survival of a sector already weakened by dramatic budget cuts over the years. ${ }^{2}$ The economic situation of suppliers (artists) and non-profit intermediaries has been the focus of most surveys, for they require urgent public aids. We believe, however, that the role of consumers should not be sidelined, especially in the long-run recovery process. The present commentary paper supports this hypothesis by providing a general overview of the situation experienced by the cultural sector since the beginning of the crisis and by singling out the main features of art consumption. Our goal is to encourage further consumer-oriented research by initiating a discussion on four main axes which appear particularly relevant in light of recent events: (1) the importance of collecting data on consumers' cultural practices; (2) consumers and digital cultural content; (3) consumers' engagement and loyalty in the arts and culture; and (4) consumers' well-being as a core benefit of art consumption. Arguments from the

\footnotetext{
1 Along with the reflexivity and hermeneutic shocks, the inventiveness shock consists for the cultural sector to provide novel, innovative, and original solutions to the crisis.

${ }^{2}$ Large-scale surveys have been carried out by organizations such as ICOM, UNESCO, NEMO, KEA, and the National Endowment for the Arts.
} 
literature on culture in times of crisis and consumer behavior theory are used as a theoretical and contextual framework, and illustrated with concrete initiatives developed by cultural agents.

\section{Art consumption in times of economic turmoil}

Contrary to common beliefs, social and economic crises can be productive periods for the arts. According to Cosslett (2020), "isolation has historically proved fruitful, and artists are producing new work all the time," and the artistic projects which have burgeoned across the world since the beginning of the pandemic corroborate this statement. ${ }^{3}$ As a matter of fact, some of the most significant art movements (e.g., expressionism and modernism) emerged as a response to political and economic uncertainty, even if unstable conjunctures can also lead to quality leveling-down, art frauds, and illicit trade (Moldoveanu and Ioan-Franc 2011; Euwe and Oosterlinck 2017). What is more, the key role of art and culture during economic downturns and their role in education and entertainment are widely acknowledged. Participation in culture and the arts is indeed viewed as an escapist therapy to isolation (Tajtàkovà et al. 2019). For this reason, art consumption and participation tend to remain relatively dynamic in both crisis and post-crisis times, although characterized by a "lipstick effect" suggesting that consumers tend to favor cheaper outdoor cultural activities in order to still satisfy their desire for consumption (Tajtàkovà et al. 2019). Other studies have shown that high art institutions remain visited (Sokolov 2019), whereas the high-end art market has proved to be relatively robust and quick to recover (Goetzmann et al. 2011). Therefore, one could argue that the current crisis is an opportunity for cultural institutions and industries to renew their business models and foster structural changes (Reiss 2001; Bonet and Donato 2011; McDonnell and Tepper 2014). From that perspective, and as an exogenous treatment affecting all cultural subsectors, the COVID-19 pandemic can be viewed as an unprecedented occasion for innovation and experimentation.

It is however true that global crises also generate substantial uncertainty within a field where financial and human resources may differ significantly, limiting de facto some innovation opportunities. We have witnessed this vulnerability in recent periods of economic turmoil, such as the 1973-1975, 1993 and 2008-2009 economic crises. Typically, crises of this magnitude tend to undermine an already challenging context in which cultural institutions and organizations face decreasing government funding, shifts in philanthropy, growing competition, technological changes, and rising costs of artistic labor (McDonnell and Tepper 2014). Since it strongly relies on government funding in Europe (Bonet and Donato 2011) and private patronage and donations in the United-States (Renz 2003), the cultural sector remains particularly precarious and all the more vulnerable in uncertain times. To some extent, the current pandemic shares some similarities with the 2008 financial crisis, since

\footnotetext{
3 This is especially the case of street art projects. See, for example, https://www.smithsonianmag.com/ travel/how-street-artists-around-world-are-reacting-to-life-with-covid-19-180974712/
} 
the economic recession predicted by economists is likely to affect the sector's three main sources of revenue: government funding, private donations, and income generated by sales and ticketing. Consistent with what Bonet and Donato (2011) found for 2008-2009, and despite the approval of emergency funds and exceptional credits, future budget restrictions from governments and private sponsors are a likely scenario of yet-unknown proportions, as well as the bankruptcies of profit and nonprofit cultural structures. Household spending and consumption practices have also proved to decrease in times of recession, with cultural goods and services at the forefront since, unlike physiological needs, they are not considered vital. Nonetheless, despite the long-standing socio-economic consequences of 2008, it is encouraging to see that most leading cultural institutions (museums, concert venues, theatres, etc.) are still standing, just like art sales have experienced significant growth, and creative industries have continued to flourish in major cities and local urban hubs.

Yet the 2020 sanitary crisis differs from the 2008 economic downturn. One of its main distinctive features is the temporary closure of all cultural structures and the suspension of on-site cultural activities. To that must be added an unprecedented systemic uncertainty, resulting from the combination of three types of uncertainty (biological, economic, and idiosyncratic), and causing severe asymmetric effects on the economy (Dasgupta et al. 2020). On the supply side, this systemic uncertainty seriously complicates planning, decision, and production making. On the demand side, it generates "a variety of individual-level responses, making it almost impossible to offer clear solutions" (Dasgupta et al. 2020: 2). In fact, the pandemic has challenged the fundamentals of the expected utility theory (EUT), by preventing suppliers and consumers from identifying the probable outcomes of specific decisions amid the crisis, and from taking optimal decisions based on prior experiences. In such a situation, procedural rationality tends to prevail in the decision-making process, to reach not optimal but "reasonably good" outcomes (Simon 1957; Dasgupta et al. 2020). In light of this, it is necessary to assess the extent to which measures taken to cope with COVID-19 have-momentarily or durably-modified consumption patterns.

The experience deriving from consuming the arts and culture is inherently multifaceted. It can be individual or collective, physical or virtual, active or passive, public or private, on-site or in private environments, open-air or indoor, all these categories not being mutually exclusive. Evidently, art consumption is not only concerned with the purchase of tangible cultural goods (e.g., works of art, books, records, DVDs, video games, etc.). The industry of cultural services and participation in cultural events are part of the broad consumption experience (e.g., visiting exhibitions, attending concerts, theatre plays, traditional folklore, etc.). The distinction between high and popular culture finds its origins in sociological and economic theories which state that consuming art and culture requires symbolic capital, which varies amongst socioeconomics groups (DiMaggio and Useem 1978; Bourdieu 1979; Andreasen and Belk 1980; DiMaggio and Mohr 1996). ${ }^{4}$ While the debate

\footnotetext{
${ }^{4}$ McDonnell and Tepper (2014) propose a four-category typology which includes: i) Non-profit/High culture (art museums, theatres, ballet, orchestra, operas, playhouses, public radio stations); ii) Non-profit/ Popular Culture (libraries, parades, cultural and ethnic festivals, indie/college radio stations, aquariums,
} 
Table 1 Main characteristics of the consumption of the arts and culture

\begin{tabular}{ll}
\hline Characteristic of the supply & Corollary characteristic of the supply \\
\hline Good & Service \\
Material & Immaterial \\
High & Popular \\
Consumption pattern & Corollary consumption pattern \\
Individual & Collective \\
Free/open access & Admission fees \\
Mainstream & Niche \\
National/international & Local \\
Physical & Virtual \\
Active & Passive \\
Public & Private \\
On-site & At home/private environment \\
Open-air & Indoor \\
\hline
\end{tabular}

Source: author

surrounding these two categories is out of the scope of this paper, the consumption process remains experiential, characterized by different levels of proximity and interactions with the good and service. Cultural operators can operate at a local, national, or international levels (with different levels of reputation), and specialize in mainstream or indie cultural content. The access to the latter can be free or by payment, with prices ranging from a few euros to several million (in the case of the art market). When purchasing cultural goods or attending cultural events, people simultaneously seek functional, symbolic, social, and emotional benefits, with different degrees of experience (Hirschman and Holbrook 1982; Botti 2000; Colbert and StJames 2014). Those degrees of experience not only depend on the artistic discipline in question and on the nature of the goods and services consumed, but also on the configuration of cultural markets that vary in space and time (Moldoveanu and IoanFranc, 2011). Table 1 summarizes the main patterns of art consumption.

The shutdown period has substantially affected a key pattern of art consumption: its social and experiential dimension. Whereas some consumption patterns have temporarily disappeared since the beginning of the crisis (i.e., collective, physical, on site, indoor, public, etc.), some others have dramatically risen for they are less affected by social distancing (i.e., digital/virtual, private, home, free and openaccess). ${ }^{5}$ Additionally, crucial parameters such as the structure's status (e.g., public or private, commercial or non-profit), its field of specialization, and missions (e.g., education, entertainment, conservation, research, etc.) may have impeded efficient

\section{Footnote 4 (continued)}

halls of fame); iii) Commercial/High culture (art galleries, jazz clubs, arthouse/independent movie theatres, for-profit museums); iv) Commercial/popular culture (bookstores, record stores, comic books stores, drive-in movie theatres, amusement parks, fairgrounds).

5 Note that Netflix, Amazon Video, and other similar platforms offer charged services that have been particularly demanded during the lockdown period. 
crisis management. Further, while the closing measures applied to all types of structures (e.g., concert venues, museums, theatres, creative industries, auction houses, etc.), the easing of containment measures and the reopening of countries reveal differential and uncoordinated treatments. On the one hand, museums, art galleries, and other indoor cultural spaces are progressively being allowed to reopen under strict social distancing measures (e.g., online reservation, limited number of individual visitors per hour, floor marking, etc.). On the other hand, the future of some other structures remains extremely uncertain at this juncture, as is the case of theatres, concert venues, outdoor and indoor festivals, opera, etc. The performing arts, which require a minimum audience in situ, can hardly comply with such measures. Operating at a limited seating capacity would even lead to significant income loss and cost inefficiency. ${ }^{6}$ Despite these institutions' economic weight, public authorities and policymakers are still struggling to agree on economic reopening plans that would simultaneously ensure the security of artists, organizers, and attenders. As a consequence, several cultural sectors remain in a grey zone regarding their future operating procedures. The lack of coordinated directives creates asymmetric effects among cultural operators that prevent the whole sector from recovering homogeneously.

The prolonged suspension of some cultural activities requires significant state interventions (e.g., direct financial aid, subsidies, emergency funds, tax incentive for donations) to guarantee their survival in the short term and viability in the long run (Reiss 2001; Bonet and Donato 2011). Financial and logistical support of artists and cultural agents must therefore be encouraged, just as the necessity of considering the cultural sector as an ecosystem within which different stakeholders interact with each other permanently. Amongst the proposals made by economists, Benhamou and Ginsburgh (2020) are in favour of a "New Deal" that would weigh each cultural subsector based on its contribution to the general economy. In that respect, the recovery process should not focus on consumption but on investments in the lower end of the pyramid to relieve authors, artists, and creative people, as well as fragile or unfunded structures, from financial pressure. ${ }^{7}$ We further argue that these financial supports, and future funding, should be designed according to each cultural subsectors' inherent characteristics and consumption modalities, and by considering the ability of eligible cultural structures to endure systemic uncertainty.

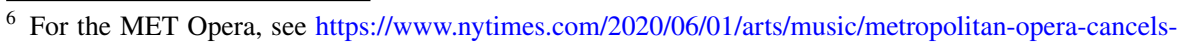
season-virus.html

${ }^{7}$ In Belgium, some institutions such as the Opéra royal de Wallonie or Brussels cultural centre Flagey did not claim government aids as their annual grants allow them to overcome the crisis. See https:// www.rtbf.be/info/belgique/detail_fonds-d-urgence-pour-le-soutien-a-la-culture-accord-sur-la-repartitio n-des-premieres-aides?id=10520417\&fbclid=IwAR2riVKgXRfS2Zo3dfTm-YXrEGL0wyAJlbmUG8iry oKKJ6F38gKfYCr7LqQ.
} 


\section{For a consumer-oriented approach}

As discussed above, the importance of artists and intermediaries for making supply meet demand constitutes a reasonable argument for funding. However, we believe that the publics and consumers should not be neglected in the recovery process. The social experience of art consumption has been severely affected by the sanitary crisis, and the consumers' willingness to attend large-scale cultural manifestations and to pay for online cultural goods and services will be decisive for the future of the sector. Here, we address four directions in consumer research that might help cultural institutions and industries readjust their operating mode in light of recent events and improve their ability to cope with similar situations in the future.

(1) Gathering data on consumers' cultural practices: Data on consumers' practices in the cultural field remains relatively limited, and cultural operators rarely have the human and financial resources to carry out extensive research aiming to profile consumption patterns (Turbide and Laurin 2009; Syen Kang 2010). ${ }^{8}$ Local cultural operators' websites and statistical tools are usually limited to demographic information on their publics and are not always implemented for marketing purposes or predictive analyses. If education and incomes are known to influence art consumption (Kurabayashi and Ito 1992), the current crisis has urged cultural institutions and industries to get a better sense of what their publics and consumers need, value, and expect when traditional consumption patterns are seriously challenged. This requires accurate knowledge on the publics, supported by data that might assist cultural operators to develop and take appropriate actions (e.g., adjustment of supply) in the short, medium, and long term. Put differently, efforts should be made to understand consumers' incentives to attend cultural events or to purchase cultural goods in extraordinary circumstances. While knowledge about demand is essential to ensuring financial sustainability and competitive strength (Troilo et al. 2014), it may also help reduce structural issues and risks of bankruptcy in hard times. Furthermore, there is a high likelihood that the current crisis will make people more risk-averse, with future consumption behaviours that may vary depending on how each individual has experienced the crisis. While radical scenarios might be stopping all cultural activities, or continuing attending cultural events as if the crisis had never happened, some individuals might behave moderately by reducing time and money spent in certain on-site cultural activities, or selecting the less risky operators that are able to implement efficient sanitary measures. Since the arts and culture remain non-essential purchases, the swift from an optimal to a rational procedure in making-decision might therefore affect consumption behaviours more durably than expected (Dasgupta et al. 2020), and create new forms of inequalities among cultural institutions and industries. Knowing to what extent and under which conditions people will be willing to consume the arts and culture in the near future is therefore crucial for cultural operators to provide appropriate responses to these new

\footnotetext{
8 The work of data collection by governmental institutions (e.g., Eurostat, National Institutes of Statistics, etc.) is usually limited to factual information by subsectors, not on cultural consumption patterns per se.
} 
consumption behaviors. Both the positive and negative experiences they have gained throughout the pandemic will constitute a significant advantage should similar crises happen again, since decision-makers have now clues on how to deal with the supply and demand for cultural goods and services in times of pandemics, which should facilitate the decision-making process. To guarantee the gathering of relevant and exploitable data, the building or reinforcement of alliances between the cultural sector with universities might be an option for ensuring relevant methodologies and data management that might serve both practitioners and researchers' interests. The role of cross-sectoral representative bodies, which have carried out surveys to report local information, is also central in those alliances, especially to reinforce connexions between academics and professionals and to foster data and information sharing. Joint work based on accurate data may enable the publication of more regular and systematic reports on cultural consumption practices, aiming to strengthen funding applications for governmental or private financial aids.

(2) Consumers and the digital cultural experience: In the first months of the crisis, the cultural sector has experienced an increasing demand for digital content directly accessible from private households. Consumers have been eager to entertain themselves and this behavior has emphasized the importance of culture in everyday life. Cultural institutions and industries have tried to be as responsive as possible to this growing demand by engaging in digital innovations and systematizing the use of alternative dissemination tools of cultural content, such as virtual exhibitions, "question and answer" sessions with curators and artists, online live music festivals, 3D concerts, free access to material and video archives (recorded ballets, etc.), online art sales, etc. The main characteristic of those alternatives is their free and open access, with the aims of showing dynamism and solidarity. Although the digital consumption of art and culture is not per se a recent innovation, the crisis has undoubtedly raised three main issues: the delay or inability of some cultural operators to enter the digital era efficiently; the short-term necessity of moving to an exclusively online format (as well as the sustainability of such a constraint); and the opportunity for reaching a broader audience, including new publics.

The race for digital content has revealed some disparities among cultural institutions and industries, some of them being less willing or less prepared than others to cope with the crisis, depending on their level of engagement in innovation. While the crisis has certainly been profitable to industries for which innovation and digitization are core strategies in their business model (e.g., streaming platforms such as Netflix, Spotify, Deezer, Amazon Video, etc.), many traditional institutions such as museums and theatre venues fell behind on this innovation process. They had no choice but to rapidly rethink their operating mode by increasing their online visibility, creating new content, and digitizing their collections (Rifkin 2000; Borowiecki and Navarrete 2017). ${ }^{9}$ Even though moving online is not truly innovative (Négrier and Teillet 2020), this lack of preparedness was particularly noticeable in terms of frequency of online posts, broadcast and video quality, and the ability to effectively

\footnotetext{
9 In 2014, the digitization of heritage collection was estimated at $17 \%$ only (cited in Borowiecki and Navarrete 2017).
} 
reach and interact with an online audience. Even if public authorities were to seriously consider investing in digital innovations, the risk of increasing inequalities between leading and local institutions is non-negligible. The nature of some cultural content may not be suitable to digitization, the institution may not have the financial resources to develop digital projects, and employees (usually humanists) may not be trained in digital technologies. ${ }^{10}$ Future research is therefore needed to explore the potential of digitization, for feasibility and policy purposes, but also to examine its impact on publics and their consumption experience, since patterns are likely to change in a foreseeable future. In this process, more systematic alliances with computer scientists and companies specialized in digital tools should be considered.

As a matter of fact, the crisis has also incited some intermediaries to re-examine their business models. Will concerts and large-scale festivals happen again, and if so, under which terms and conditions? If the decision to perpetuate and accentuate the online model is taken, the monetization of digital content has to be considered, as well as the consumer's willingness to pay for such services, previously accessible physically. Artists, intermediaries, and the whole cultural ecosystem need to actively generate inner revenues to remain operational, without relying exclusively on external private or governmental funding. If one of the consequences of the sanitary crisis appears to be the rise and expansion of online cultural supply-a process that might accelerate with the advances in artificial intelligence (AI) - a balance must be struck between physical and digital experiences in order to preserve the added value of social experiences which participates to the cultural capital building process. Unlike digital consumption, for which customers are less able to interact with each other, physical consumption permits proximity with cultural goods and content, and contributes to developing the symbolic capital and taste for culture (Atkinson and Robson 2012). According to Botti 2000, social exchanges and interactions with peers (i.e., discussions, expressions of emotions and feelings, etc.), can hardly happen at an individual level. The complex relationship between experiential and digital experiences in the arts is therefore a compelling agenda for researchers to help cultural institutions and organizations deal with consumers' expectations and supply constraints.

Despite its limitations, digital and virtual consumption allows for innovative and interactive cultural participation (Morrone 2006). It has also proved to be beneficial for stimulating customers with experience-rich information environments (Berman 2008). As pointed out by several institutions, the opportunity to participate in free and open-access virtual cultural events has been game-changing for new publics, which can be viewed as an opportunity to democratize access to art and culture. Whether or not those new publics will become regular once institutions return to normal activities is another question that can hardly be answered without reliable data. Factors to consider in the investigation of this question include the extent to which access to digital appliances, necessary for digital experiences, is ultimately a limit to democratization. Art consumption also requires a certain degree of

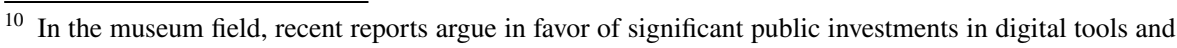
training (NEMO 2020).
} 
familiarity, immersion, and contact frequency with the arts and culture, especially at an early age (Stigler and Becker 1977; McCarthy and Jinnett 2001; Zakaras and Lowell 2008). If digital consumption can lower entry barriers and attract non-publics, the physical experience with art and culture seems unavoidable in the process of becoming regular consumers.

(3) Consumers' loyalty and engagement in the arts and culture: According to Throsby (1994), cultural consumption is a process of accumulating knowledge and experience which affects future consumption. Customer satisfaction is crucial even in the art business, where success is mostly measured by customer's experience and participation (Anderson et al. 2004; Hume and Sullivan Mort 2008, 2010). One of the most striking reactions observed during the crisis is the consumers' willingness to show solidarity toward cultural operators. Seemingly, the lockdown period has generated interesting reactions from the demand side, particularly visible on social media. While the sudden cancellation of cultural events may lead to customer dissatisfaction, the out-of-control situation experienced by the cultural sector has prevented most consumers from complaining. Support and solidarity have taken multiple forms, including reimbursement renunciation, advanced subscription to the future seasons (for example, in theatre), online purchases, messages of support, and donations. Put differently, recent events have revealed the extent of consumers' engagement and loyalty to cultural operators, and reciprocally, the necessity for cultural institutions and industries to know their consumers' expectations. Prior research has already demonstrated that consumer satisfaction and active engagement in the arts and culture is a necessary condition to increase the likelihood of reiterating consumption experiences (e.g., Arnould and Thompson 2005; BourgeonRenault et al. 2006; Hume 2008; Troilo et al. 2014; Yee-Man Siu et al. 2016). Active engagement is part of cultural consumption, which can contribute to customer satisfaction once perceived as personally rewarding and joyful (Yee-Man Siu et al. 2016; O'Reilly et al. 2014). The social experience offered by cultural consumption, as well as the opportunity to experience unique emotions, are crucial for developing loyalty mechanisms (Colbert and St-James 2014). By connecting with their public, adjusting the supply through appropriate marketing strategies (Yee-Man Siu et al. 2016), and making customers feel they are part of the cultural experience, institutions and industries can increase the feeling of belonging to a community. Such a feeling of belonging is critical when facing uncertain times, mostly to incite financial support. Furthermore, a high level of satisfaction can lead to new consumers' adherence, which, by snowball effect, may increase and reinforce the capital of loyal customers in hard times (Fornell et al. 2010).

(4) Consumers' well-being as a core benefit of art consumption: Arts and culture are consumed for various reasons such as education, leisure, evasion, relaxation, delectation, self-reflexivity, etc. (Russell and Levy 2012). The strong relationship that cultural suppliers and intermediaries can tie with consumers is chiefly due to the hedonic value of cultural goods and services, or the enjoyment that results from their consumption. According to Caldwell (2001), "customers always seek a pleasing experience when attending arts activities." The social and emotional function of art consumption is also reflected in the creative, affective, and symbolic dimensions of consumer behaviors (Hirschman and Holbrook 1982; Arnould and Thompson 
2005). Its positive impact on well-being and mental health has been acknowledged by scientists for reducing tension, anxiety, and frustration (e.g., Matarasso 1997; Kim and Kim 2009). If future studies should assess how art consumption has helped individuals cope with the global health crisis, recent events seem to corroborate, if not reinforce, the fundamental role of art and culture in issues of individual wellbeing. This represents a significant funding opportunity that cultural institutions and organizations should promote to local governments and private sponsors, by insisting on how a given society can benefit from culture as a public good in a context of increased anxiety. In this perspective, strategic alliances with educational and welfare sectors are worth considering. In-depth knowledge of consumers' needs and expectations is needed to justify funding, which is consistent with the necessity of collecting data on cultural consumption patterns in times of crisis.

\section{Conclusions}

Since the announcement of the global pandemic, and the shutdown of most cultural institutions and industries, art consumption has experienced visible, and potentially measurable, shifts. While direct and physical access to art and culture has temporarily been suspended, indirect and online access has grown significantly due to a growing demand for cultural content in a situation of anxiety and isolation. Whether the mid-and-long run impact of the pandemic on cultural consumption practices cannot be assessed yet, this commentary paper has outlined the importance of not only considering the supply side (artists and intermediaries), but the demand side as well (consumers). Despite the opportunities stemming from the crisis (e.g., inventiveness, community reinforcement and enlargement, stronger integration through digitalization, etc.), financial and logistical support will be essential to help creative people and cultural operators recover in the long run. We argue that the role of consumers should not be minimized in this recovery process. Art supply and consumption patterns are extremely heterogeneous with subsectors that have unequally been affected over the past months. This suggests that the recovery processes will differ from one subsector to another, with treatments ranging from basic social distancing measures to in-depth reassessments of business models.

In order to take into account the demand side in the recovery process, four consumer-oriented research directions have been proposed: (1) to get more systematic and accurate data on cultural consumption patterns; (2) to better assess the hedonic value of digital art consumption; (3) to reinforce consumers' engagement and loyalty toward cultural institutions, and (4) to promote individual well-being as a key benefit from art and culture. Each of them deserves to be further investigated to help cultural operators recover from this unprecedented crisis. For this purpose, the importance of building and reinforcing alliances with external partners such as schools, universities, computational scientists, education and public welfare sectors has been suggested. More accurate knowledge on consumption patterns within each subsector of arts and culture (e.g., the performing arts; fine arts; cultural industries; the art market, etc.) is indeed needed in order to better anticipate people's needs, expectations in times of crisis (but also future behaviors), to detect the emergence 
of alternative consumption patterns, and to help cultural institutions and industries avoid taking inappropriate decisions throughout the recovery process. Surveys should therefore be conducted at a national level for cultural policies, but also at an individual level for private governance and business strategies.

Acknowledgements I am thankful to Felipe Alvarez de Toledo (Duke University) for his careful reading of this paper.

Funding This commentary paper acknowledges financial support from the Belgian American Educational Foundation (B.A.E.F.).

\section{Compliance with ethical standards}

Conflict of interest The corresponding author states no conflict of interest.

Ethical approval This article does not contain any studies with human participants or animals performed by the author.

\section{References}

Anderson EW, Fornell C, Mazvancheryl SK (2004) Customer satisfaction and shareholder value. J Mark 68:172-185. https://doi.org/10.1509/jmkg.68.4.172.42723

Andreasen AR, Belk RW (1980) Predictors of attendance at the performing arts. J Consum 7:112-120. https://doi.org/10.1086/208800

Arnould EJ, Thompson CJ (2005) Consumer culture theory (CCT): twenty years of research. J Consum 31:868-882. https://doi.org/10.1086/426626

Atkinson S, Robson M (2012) Arts and health as a practice of liminality: managing the spaces of transformation for social and emotional well-being with primary school children. Health Place 18:13481355. https://doi.org/10.1016/j.healthplace.2012.06.017

Benhamou F, Ginsburgh V (2020) La pyramide inversée pour relancer l'économie de la culture. In: Terra Nova. Available via https://tnova.fr/notes/la-pyramide-inversee-pour-relancer-l-economie-de-laculture

Berman S (2008) Performing online: PR through web gives arts and cultural institutions new power. Public Relat Tact 15:21

Bonet L, Donato F (2011) The financial crisis and its impact on the current models of governance and management of the cultural sector in Europe. J Cult Manag Pol 1:4-11

Borowiecki KJ, Navarrete T (2017) Digitization of heritage collections as indicator of innovation. Econ Innov New Technol 26:227-246. https://doi.org/10.1080/10438599.2016.1164488

Botti S (2000) What role for marketing in the arts? An analysis of arts consumption and artistic value. Int J Arts Manag 2:14-27. https://www.jstor.org/stable/41064697?seq=1\#page_scan_tab_contents

Bourdieu P (1979) La distinction. Critique Sociale du Jugement, Paris, Les Editions de Minuit

Bourgeon-Renault D, Urbain C, Petr C, Le Gall-Ely M, Gombault A (2006) Experiential approach to the consumption value of arts and culture: the case of museums and monuments. Int J Arts Manag 9:35-47. https://doi.org/10.1177/076737010702200202

Caldwell M (2001) Applying general living systems theory to learn consumers' sense making in attending performing arts. Psychol Mark 18:497-511. https://doi.org/10.1002/mar.1018

Colbert F, St-James Y (2014) Research in arts marketing: Evolution and future directions. Psychol Mark 31:566-575. https://doi.org/10.1002/mar.20718

Cosslett R H (2020) Be it Hopper pastiche or Hockney original, art offers vital comfort in times of crisis. In: The Guardian. Available via https://www.theguardian.com/commentisfree/2020/apr/08/hoppe r-hockney-art-comfort-crisis-coronavirus

Dasgupta U, Jha CK, Sarangi S (2020) Procedural rationality in the time of COVID-19. Econ Political Wkly 55:13 
DiMaggio P, Mohr J (1996) The intergenerational transmission of cultural capital. Res Soc Stratif Mobil 14:167-199. https://doi.org/10.1353/sof.2010.0087

DiMaggio P, Useem M (1978) Social class and arts consumption: the origins and consequences of class differences in exposure to the arts in America. Theory Soc 5:141-161. https://doi.org/10.1007/ BF01702159

Euwe J, Oosterlinck K (2017) Art price economics in the Netherlands during World War II. JAMS 1(1):47-67. https://doi.org/10.23690/jams.v1i1.6

Fornell C, Rust RT, Dekimpe MG (2010) The effect of customer satisfaction on consumer spending growth. J Mark Res 47:28-35. https://doi.org/10.1509/jmkr.47.1.28

Goetzmann WN, Renneboog L, Spaenjers C (2011) Art and money. Am Econ Rev 101:222-226. https:// doi.org/10.1257/aer.101.3.222

Hirschman EC, Holbrook MB (1982) Aesthetics, ideologies and the limits of the marketing concept. J Mark 47:45-55. https://doi.org/10.1177/002224298304700306

Hume M (2008) Satisfaction in performing arts: the role of value. Eur J Mark 42:311-326. https://doi. org/10.1108/03090560810852959

Hume M, Sullivan Mort G (2008) Understanding the role of involvement in customer repurchase of the performing arts. J Nonprofit Public Sect Mark 20:299-328. https://doi.org/10.1080/1049514080 2225016

Hume M, Sullivan Mort G (2010) The consequence of appraisal emotion, service quality, perceived value and customer satisfaction on repurchase intent in the performing arts. J Serv Mark 24:170-182. https://doi.org/10.1108/08876041011031136

Kim S, Kim H (2009) Does cultural capital matter?: Cultural divide and quality of life. Soc Indic Res 93:295-313. https://doi.org/10.1007/s11205-008-9318-4

Kurabayashi Y, Ito T (1992) Socio-economic characteristics of audiences for western classical music in Japan: a statistical analysis. In: Towse R, Khakee A (eds) Cultural economics. Springer, Berlin, pp 275-287

Matarasso F (1997) Use or ornament? The social impact of participation in the arts. Comedia, Stroud

McCarthy K F, Jinnett K (2001) A new framework for building participation in the arts. RAND, Santa Monica. Available via https:/www.rand.org/pubs/monograph_reports/MR1323/

McDonnell TE, Tepper SJ (2014) Culture in crisis: deploying metaphor in defense of art. Poetics 43:2042. https://doi.org/10.1016/j.poetic.2014.01.002

Moldoveanu M, Ioan-Franc V (2011) The impact of the economic crisis on culture. Rev Gen Manag 14(2):15-35. https://managementgeneral.ro/pdf/2_2011_2.pdf

Morrone A (2006) Guidelines for measuring cultural participation. Available via https://www.uis.unesc o.org/template/pdf/cscl/framework/CUL_particip.pdf

Négrier E, Teillet P (2020) Les trois chocs culturels du COVID-19. Presses Universitaires de Grenoble, Grenoble

NEMO (2020), Survey on the impact of the COVID-19 situation on museums in Europe. Final report. Available via: https://www.nemo.org/fileadmin/Dateien/public/NEMO_documents/NEMO_COVID 19_Report_12.05.2020.pdf

O'Reilly D, Rentschler R, Kirchner TA (2014) The Routledge companion to arts marketing. Taylor \& Francis Group, New York

Reiss AH (2001) Arts response in time of crisis. Fund Rising Manag 26:35-36

Renz L (2003) An overview of revenue streams for nonprofit arts organizations. Reader 14(2). Available via: https://www.giarts.org/article/overview-revenue-streams-nonprofit-arts-organizations

Rifkin J (2000) The age of access: the new culture of hypercapitalism, where all of life is a paid-for experience. Putnam Publishing Group, New York

Russell CF, Levy SJ (2012) The temporal and focal dynamics of volitional reconsumption: a phenomenological investigation of repeated hedonic experiences. J Consum 39:341-359. https://doi. org/10.1086/662996

Simon AH (1957) Models of man. Wiley, New York

Sokolov M (2019) Cultural capital and social revolution: arts consumption in a major Russian city 19912017. Poetics 72:1-16. https://doi.org/10.1016/j.poetic.2018.10.005

Stigler G, Becker G (1977) De gustibus non est disputandum. Am Econ Rev 67:76-90. https://www.jstor .org/stable/1807222

Syen Kang D (2010) Understanding of consumption behaviors in art and cultural sectors for developing successful communication plans. J Target Meas Anal Mark 18:263-279. https://doi.org/10.1057/ jt. 2010.13 
Tajtáková M, Žák Š, Filo P (2019) The lipstick effect and outdoor cultural consumption in Slovakia in times of crisis. Ekon Cas 67:607-628. https://doi.org/10.6084/m9.figshare.11605491

Throsby D (1994) The production and consumption of the arts: a view of cultural economics. J Econ Lit 32:1-29. https://www-jstor-org.proxy.lib.duke.edu/stable/2728421?origin=JSTOR -pdf\&seq=1\#metadata_info_tab_contents

Troilo G, Cito MC, Soscia I (2014) Repurchase behavior in the performing arts: do emotions matter without involvement? Psychol Mark 31:635-646. https://doi.org/10.1002/mar.20724

Turbide J, Laurin C (2009) Performance measurement in the arts sector: the case of the performing arts. Int J Arts Manag 11:56-71. https://doi.org/10.1007/978-3-030-46796-8_11

UNESCO (2020) In moments of crisis, people need culture. Available via https://en.unesco.org/news/ moments-crisis-people-need-culture. Page Accessed on 1 May 2020

Yee-Man Siu N, Kwan HY, Jun-Feng Zhang T, Ka-Yan Ho C (2016) Arts consumption, customer satisfaction and personal well-being: a study of performing arts in Hong Kong. J Int Consum Mark 28:77-91. https://doi.org/10.1080/08961530.2015.1089806

Zakaras L, Lowell JF (2008) Cultivating demand for the arts. Arts learning, arts engagement, and state arts policy. RAND Corporation, Santa Monica 